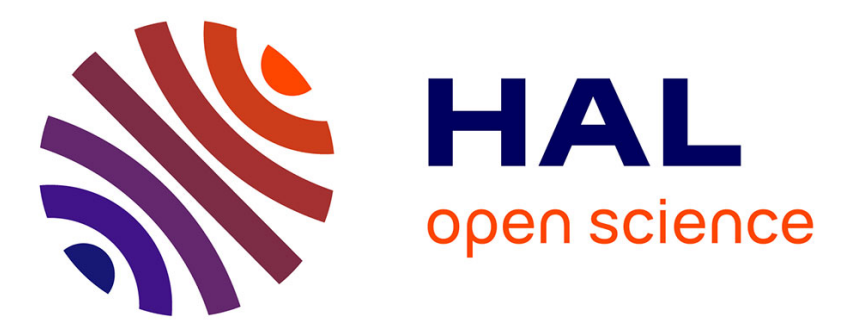

\title{
Simultaneous heat-flow differential calorimetry and thermogravimetry for fast determination of sorption isotherms and heat of sorption in environmental or food engineering
}

Jean Henry Ferrasse, Didier Lecomte

\section{To cite this version:}

Jean Henry Ferrasse, Didier Lecomte. Simultaneous heat-flow differential calorimetry and thermogravimetry for fast determination of sorption isotherms and heat of sorption in environmental or food engineering. Chemical Engineering Science, 2004, 59 (6), p.1365-1376. hal-01845406

\author{
HAL Id: hal-01845406 \\ https://hal.science/hal-01845406
}

Submitted on 18 Nov 2018

HAL is a multi-disciplinary open access archive for the deposit and dissemination of scientific research documents, whether they are published or not. The documents may come from teaching and research institutions in France or abroad, or from public or private research centers.
L'archive ouverte pluridisciplinaire HAL, est destinée au dépôt et à la diffusion de documents scientifiques de niveau recherche, publiés ou non, émanant des établissements d'enseignement et de recherche français ou étrangers, des laboratoires publics ou privés. 


\title{
Simultaneous heat-flow differential calorimetry and thermogravimetry for fast determination of sorption isotherms and heat of sorption in environmental or food engineering
}

\author{
Jean-Henry Ferrasse ${ }^{1}$, Didier Lecomte* \\ UMR-CNRS 2392, Laboratoire de G'enie des Proc'ed'es des Solides Divis'es, Ecole des mines d'Albi-Carmaux, Route de Teillet-81013, \\ Albi cedex 09, France
}

\begin{abstract}
A new experimental technique is described for the determination of desorption characteristics for engineering purposes. A TGA-DSC set-up is used in isothermal mode to achieve the thermal desorption of deformable standard materials like microcrystalline cellulose and kaolin in dry air. Assumptions on heat and mass transfer are made and discussed in order to derive desorption isotherms and heat of sorptions from the calorimetric and gravimetric signals. The method is rapid and accurate for high-temperature desorption processes $T \geqslant 40^{\circ} \mathrm{C}$. It is particularly reliable for small water activity values $0 \leqslant a_{w} \leqslant 0.4$ where a good agreement with standard methods is observed in spite of small apparent diffusion coefficients $D \cong 10^{-10} \mathrm{~m}^{2} \mathrm{~s}^{-1}$ for the two products tested. The method is suitable for heat sensitive biological products because of the small residence time in the furnace ( 1 or $2 \mathrm{~h})$.
\end{abstract}

Keywords: Phase equilibria; TGA; Instrumentation; Food processing; DSC; Desorption

\section{Introduction}

In various scientific domains, food science and processing, material science, environmental sciences, the combination of water and solid materials is usually described by the water activity $a_{w}$. Water activity is a major factor in characterizing the quality, the durability and the safety of a product (Franks, 1991). Drying operations in the food or environmental processes usually aim at lowering the water activity (Bassal, 1993). Sorption equilibrium curves are usually displayed as a number of moles or a mass of water versus the activity of water at equilibrium.

The different measurement methods have been classified by Leung (1983) and Rahman (1995). Two classes of methods are mainly used by researchers; methods where the pressure above a known mass of sample is measured, and

\footnotetext{
* Corresponding author. Tel.: +33-563-49-3093; fax: $+33-563-49-3243$.

E-mail address: lecomte@enstimac.fr (D. Lecomte).

${ }^{1}$ Present address: Département Génie Chimique-Génie des Procédés, IUT de Marseille, 142 traverse Charles Susini, Université d'Aix-Marseille 3, 13388 Marseille Cedex 13, France.
}

methods in which the pressure above the sample is fixed and the mass measured. Similar methods are used in adsorption science and are referred to as manometric and gravimetric methods (Rouquerol et al., 1999).

In food science and engineering, Rao and Rizvi (1986) report the use of manometric methods but asserts these methods are not suitable for materials containing large amounts of volatile or undergoing respiration process. The freezing point depression technique reported by Rahman (1995) seems to give reliable values for higher activities (above $0.85)$, but the range of temperature is narrow.

A very straightforward and widely used gravimetric method is to store a sample in a chamber at controlled temperature and vapour pressure. The mass is recorded at different time intervals until a constant value is observed. Constant relative humidity can be obtained by placing saturated salt solutions in the enclosure (Rahman, 1995). Aqueous solutions with different concentrations may also be used (Collins, 1933). The principal inconvenience of the method is its slowness due to mass transfer both in the material and in the air. Improvements can be made by fractioning the sample and enhancing convective mass transfer in the chamber (Ibeka and Blaisdell, 1982). A group of 
European research laboratories developed a reference system : reference material, standard equipment and procedure, evaluation of results (Spiess and Wolf, 1987; Jowitt and Wagstaffe, 1989). The reference material (Microcrystalline Cellulose Avicel PH 101 known as MCC) was chosen for its stability and constant availability.

The use of saturated salt solutions can be avoided by feeding the cabinet with a gas stream at constant vapour pressure, generally moist air. The relative humidity of the air is therefore measured by psychrometric instruments either directly (dew point) or indirectly (wet bulb temperature, capacitive hygrometers). The main difficulty of the method is to keep a constant level of moisture in the cabinet and to measure it with a good accuracy. Dew-point sensors are very precise at high activity, but cannot be used at low activities (Prior, 1979). Capacitive sensors show a good accuracy on a wide range of air moisture content but are sensitive to gas adsorption by organic volatiles and thus subject to ageing. To stabilize the air moisture content, it is possible to achieve a mixture of two air flows of different moistures (Méot et al., 1996) or to saturate air and heat it up to the required temperature (Weisser, 1986). Baucour and Daudin (1999) generates calibrated moist air by successive isothermal pressure drops across diaphragms from an initially saturated moist air. The experimental set-up enables to measure high activity values $(0.88-0.98)$. For temperatures above the boiling point, Loncin (1988) showed that water activity is only a function of temperature at atmospheric pressure. Bassal et al. (1993) proposed a method based on the equilibration of food samples in contact with pure vapour. Due to the absence of external diffusion and temperature above $100^{\circ} \mathrm{C}$, equilibrium is reached rapidly (48 $\mathrm{h})$.

Other methods (isiopiestic method, suction potential method, osmometric method) are described by Rao and Rizvi (1986). At least, the Landrock and Proctor method (1951), an extrapolation method based on saturated salt solutions, does not require thermodynamic equilibrium.

Except the last cited method, all methods require a long period of stabilization due to internal and external mass transfer, between a few days and a few months depending on the size of the sample, the order of magnitude of mass transfer diffusion and the initial moisture difference between the carrier gas and the surface of the sample. This delay causes measurements problems for biological products at high activities or high temperature where microbial and fungi proliferation and enzymatic oxidation alter the properties of the initial product. For example little work on water activity of sewage sludge is available in the literature (Vaxelaire et al., 2000), measuring difficulties are also reported in this particular scientific area (Ferrasse, 2000).

The methods presented in this short review require considerable experimental care. Numerous factors like temperature stability, concentration and temperature gradients, volume ratios (e.g.: sample/cell), frequency of opening, heterogeneity, etc. influence the results and until now, no method totally meets requirements of accuracy, simplicity and speed (Rahman, 1995).

A major disadvantage of the saturated salt methodthough this method is now widely adopted as a standard (Jowitt and Wagstaffe 1989) - is the small number of experimental points. Due to the limitation in the use of saturated salts, an average of 8-10 experimental points is used for the determination of sorption isotherms with difficulties arising for low and high activities measurements. Sorption isotherm models have been widely described in the literature for food (Iglesias and Chirife, 1982; Wolf et al., 1985), food-based materials (Iglesias and Chirife, 1982), and more recently for waste (Vaxelaire et al., 2000). They usually incorporate 2 or 3 parameters, thus confident parameter estimation from very little experimental data is difficult to achieve. In a cooperative study within the framework of the COST 90 program, various European laboratories determined the mean adsorption isotherms of MCC and food materials (apple pectin, potato starch,...). The 24 laboratories used the same experimental procedure and the same set-up to perform an important number of experiments. These data were examined in term of mean, standard deviation, repeatability standard deviation and reproducibility standard deviation. It resulted in a mean adsorption isotherm curve for 10 water activities at $25^{\circ} \mathrm{C}$ and standard deviations for each point (Wolf et al., 1985).

The fitting of sorption isotherms with model equations allows the determination of a function usually expressed as followed:

$a_{w}=f(X, T)$,

where $X$ is the moisture content:

$X=\left(m-m_{0}\right) / m_{0}$.

Model equations are very useful to determine the total heat of sorption. Indeed, the total heat of sorption is defined by the Clausius-Clapeyron law:

$\Delta H_{t}=-\left.\frac{R}{M} \frac{\partial \ln p_{v}(X, T)}{\partial \frac{1}{T}}\right|_{X}$.

The total heat of sorption is the sum of the latent heat of vaporization and the isosteric heat of sorption:

$\Delta H_{t}=\Delta H_{\mathrm{st}}+\Delta H_{v}$,

where

$\Delta H_{\mathrm{st}}=-\left.\frac{R}{M} \frac{\partial \ln a_{w}(X, T)}{\partial \frac{1}{T}}\right|_{X}$.

The isosteric heat of sorption can be calculated using Othmer's methods (Othmer, 1940; Beristain et al., 1999) using Eq. (3) and direct measurements of the vapour pressure $p_{v}(X, T) \mid$. It can be alternately computed from the temperature shift of the isotherms, using Eq. (5). An average value of $\Delta H_{\mathrm{st}}$ between two temperatures $T_{1}$ and $T_{2}$ is obtained by 
integration of Eq. (5) at constant $X$ :

$\Delta H_{\mathrm{st}}=R \ln \left(a_{w 2} / a_{w 1}\right)\left(\frac{1}{T_{1}}-\frac{1}{T_{2}}\right)^{-1}$,

where $a_{w 1}$ and $a_{w 2}$ are the activities of the material at temperatures $T_{1}$ and $T_{2}$.

Using Eq. (6) and the data and confidence intervals established by Wolf et al. (1985) and Iglesias et al. (1989) and Chirife and Iglesias (1992) showed important errors in the calculations of the heats of sorption (typically $39 \%$ for microcrystalline cellulose (MCC) at $X=0.08$ and $40^{\circ} \mathrm{C} \leqslant T \leqslant 60^{\circ} \mathrm{C}$ ).

An alternative way to calculate the heat of sorption is to make a formal differentiation of the Clausius-Clapeyron equation (Eq. (3)). The method requires that coefficients are expressed as a function of the temperature. It was applied by Bassal (1993) and more recently by Viollaz and Rovedo (1999) using the GAB equation. It is shown (Balaban et al., 1987) that the applicability of this method is very much dependent of the type of model used and the range of application of the model. No real sensitivity analysis has been made to validate these methods.

Direct measurement of the heat of sorption is often invoked by authors to cope with these differentiation problems. Differential scanning calorimetry (DSC) is used by Beristain et al. (1999) to measure the heat of sorption of mesquite gum in the temperature range $\left(25-195^{\circ} \mathrm{C}\right)$. Thermogravimetric measurements with the same heating rate as the DSC $\left(10 \mathrm{~K} \mathrm{~min}^{-1}\right)$ allow computation of the mass loss of the sample. Mulet et al. (1999) used a very similar procedure with smaller heating rates $\left(2 \mathrm{~K} \mathrm{~min}^{-1}\right)$ for DSC measurements of the heat of sorption of cauliflower and potato starch in the temperature range $\left(25-150^{\circ} \mathrm{C}\right)$. Although the results for both research works are consistent with calculations from GAB's equation, the scanning method involves large temperature ranges - including probably temperatures above the boiling temperature - and one should consider that the heat of sorption obtained from this measurement is an average value over a large range of temperature (from ambient to above boiling temperature) and a large range of water content.

So far simultaneous calorimetric and gravimetric techniques have not been used for food or environmental engineering purposes. In the field of adsorption science, Berlier and Frère (1996) used a Setaram DSC111 for the measurement of heat of sorption and sorption isotherms of $\mathrm{CO} 2$ onto activated carbon. The calorimeter is used in isothermal mode and the sample is first outgased at $513 \mathrm{~K}$ with a pressure of $10^{-2} \mathrm{mmHg}$. Then the gas is adsorbed at different pressures and the heat and mass gain are recorded. This step-by-step method allowed to record both the adsorption isotherms and the heat of adsorption.

In the present paper, simultaneous gravimetric and calorimetric measurements using Setaram DSC111 apparatus in drying (desorption) conditions are presented. This method has been successfully applied for various products (Ferrasse et al., 2000a,b). Unlike the method described by Berlier and Frère (1996), no vacuum is necessary. It will be shown that under some particular assumptions regarding diffusional transfer in the sample, the method can provide reliable values of the heat of sorption and sorption isotherms, with a very fast time response. The assumptions and the limits of application of the method will be discussed.

\section{Material and equipment}

The experimental set-up is a Setaram DSC111 differential scanning calorimeter combined with a thermobalance as shown in Fig. 1. The furnace is made of a silver cylindrical block where two refractory tubes are inserted. Thermopiles of Tian-Calvet type (Tian, 1924; Calvet and Prat, 1956) are inserted between the refractory tubes and the furnace (height $20 \mathrm{~mm}$ ). The temperature of the furnace is controlled by an electric heater and a water cooled coil heat-exchanger. A Pt100 probe inserted into the silver block allows to control the furnace temperature either in isothermal mode or in scanning mode with an error better than $0.01 \mathrm{~K}$. The thermobalance is made of a beam supporting two platinum crucibles (diameter $4.3 \mathrm{~mm}$-height $9.85 \mathrm{~mm}$ ) which are suspended in the two refractory tubes at the level of the thermopiles. One of the crucibles (S) contains the sample, the other $(\mathrm{R})$ containing a non-reacting substance is called the reference. An electromagnetic device enables to keep the crucibles at a constant position during the measurement of the mass change. The detection limit is $1 \mu \mathrm{g}$. The crucibles are set at the level of the thermopiles which measure the heat flow exchanged with the furnace. The detection limit of the heat flow is $5 \mu \mathrm{W}$ in isothermal mode

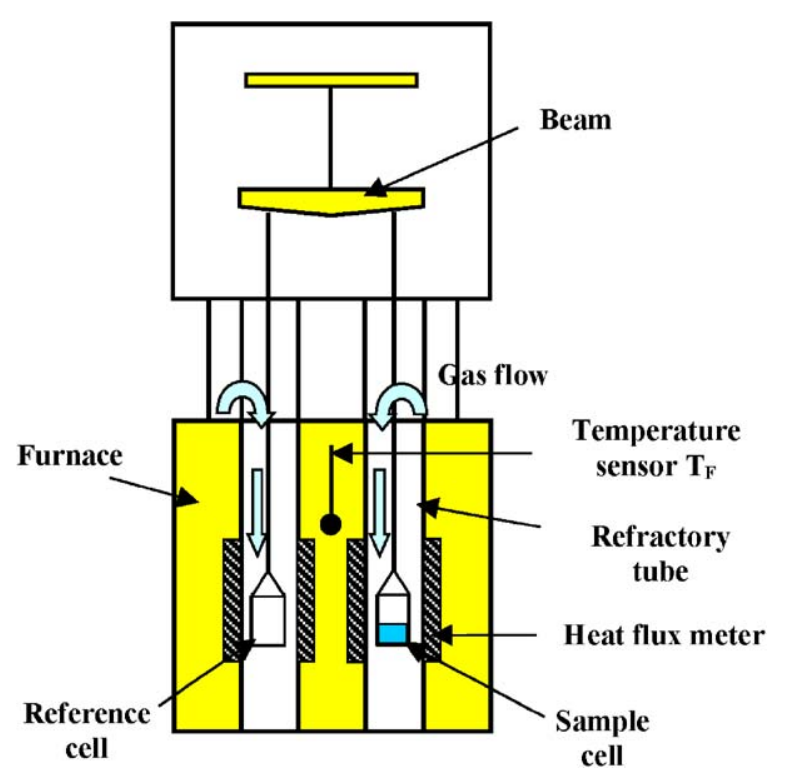

Fig. 1. Schematic view of the experimental set-up: TG-DSC 111 Setaram. 
and $15 \mu \mathrm{W}$ in scanning mode. The relative error on the heat flow measurement is $1 \%$. The recorded heat flow signal is the difference between the heat flows measured in the two thermopiles.

\section{Theoretical model}

In the following section, two assumptions are made:

A.1: Temperature is homogeneous in the crucible (S) and equal to the sample temperature $T_{S}$. It may vary with time and be different from the furnace temperature but the order of magnitude of the difference should be small and it will be shown furtherhow this difference may be quantified.

A.2: Moisture gradients are neglected in the material. This can be achieved using very thin samples $(\approx 1 \mathrm{~mm})$ and for relatively high moisture diffusion coefficients.

These fundamental assumptions will be discussed in Section 5.

\subsection{Measurement of the heat of sorption}

The theory of heat flow differential calorimeter (Calvet and Prat, 1956, 1963) is based of an energy balance on the reference and the sample crucibles.

The heat flows for the sample and the reference are proportional to the temperature differences between the crucibles and the furnace:

$\dot{q}_{S}=(\mathrm{UA})_{S}\left(T_{F}-T_{S}\right)$

and

$\dot{q}_{R}=(\mathrm{UA})_{R}\left(T_{F}-T_{R}\right)$.

The recorded heat-flow is the difference between the two heat flows $\dot{q}_{S}$ and $\dot{q}_{R}$ :

$\dot{q}=(\mathrm{UA})_{S}\left(T_{S}-T_{F}\right)-(\mathrm{UA})_{R}\left(T_{R}-T_{F}\right)$.

The energy balance equation for the sample and the reference are:

$\left(m(t) c_{S}+\mu_{C}\right) \frac{\mathrm{d} T_{S}}{\mathrm{~d} t}+\mathrm{UA}_{S}\left(T_{S}-T_{F}\right)=P$,

$\mu_{C} \frac{\mathrm{d} T_{R}}{\mathrm{~d} t}+\mathrm{UA}_{R}\left(T_{R}-T_{F}\right)=0$,

where $P$ is a source term in the sample crucible. The heat capacities of the sample and the reference crucibles can be assumed equal to $\mu_{C}$. The massic heat capacity of the sample $c_{S}$ is assumed constant.

In the present case, the microcalorimeter is used in isothermal mode. In Experiment S, the furnace temperature is fixed and the sample is dried (desorption process). The gas rapidly reaches the furnace temperature both in the sample and the reference cells. Eqs. (9)-(11) yield:

$\dot{q}=P-\left(m(t) c_{S}+\mu_{C}\right) \frac{\mathrm{d} T_{S}}{\mathrm{~d} t}+\mu_{C} \frac{\mathrm{d} T_{R}}{\mathrm{~d} t}$.
It is useful to perform a blank experiment (Experiment B) using an empty crucible. The corresponding calorimetric signal is

$\dot{q}_{B}=(\mathrm{UA})_{S}\left(T_{S B}-T_{F}\right)-(\mathrm{UA})_{R}\left(T_{R B}-T_{F}\right)$

and the energy balance for the blank experiment yield:

$\dot{q}_{B}=-\mu_{C} \frac{\mathrm{d} T_{S B}}{\mathrm{~d} t}+\mu_{C} \frac{\mathrm{d} T_{R B}}{\mathrm{~d} t}$.

The corrected calorimetric signal is obtained by subtracting $\dot{q}_{B}$ from $\dot{q}$ :

$\dot{q}_{C}=\dot{q}-\dot{q}_{B}$.

Although the correction is very small, it takes into account many effects such as buoyancy effects in the cell or differences of flowrates in the fluid flowing in the two cells.

The assumption is made that the reference crucible undertakes similar ambient conditions during the two experiments; thus the temperatures of the reference can be assumed equal:

$T_{R B}=T_{R}$

It is also assumed that rapidly the sample temperature in the blank experiment becomes very close to the furnace temperature, because of the quasi-steady regime in isothermal mode:

$T_{S B} \cong T_{F}$.

Using Eqs. (9) and (13) and the above approximations, a simple expression of $\dot{q}_{C}$ is obtained:

$\dot{q}_{C}=\mathrm{UA}_{S}\left(T_{F}-T_{S}\right)$

and the combination of the energy balance equations (12) and (14) yield

$$
\begin{aligned}
\dot{q}_{C}= & P-m(t) c_{S} \frac{\mathrm{d} T_{S}}{\mathrm{~d} t} \\
& +\mu_{C}\left(\frac{\mathrm{d} T_{S}}{\mathrm{~d} t}-\frac{\mathrm{d} T_{S B}}{\mathrm{~d} t}+\frac{\mathrm{d} T_{R}}{\mathrm{~d} t}-\frac{\mathrm{d} T_{R B}}{\mathrm{~d} t}\right) .
\end{aligned}
$$

With assumptions (16) and (17), this equation reduces to:

$\dot{q}_{C}=P-\left(m(t) c_{S}+\mu_{C}\right) \frac{\mathrm{d} T_{S}}{\mathrm{~d} t}$.

The application is particularly interesting in a drying or a desorption process where the energy absorbed per unit time by the material is related to the total heat of desorption:

$P=-\dot{m}(t) \Delta H_{t}(t)$.

Thus one obtains:

$\dot{m}(t) \Delta H_{t}(t)=-\dot{q}_{C}-\left(m(t) c_{S}+\mu_{C}\right) \frac{\mathrm{d} T_{S}}{\mathrm{~d} t}$.

In isothermal mode, the energy equation can be simplified assuming the heat accumulated in the sample crucible is negligible (however it is possible to keep this term). Thus 
a very straightforward equation can be obtained:

$\dot{q}_{C}=-\dot{m}(t) \Delta H_{t}(t)$.

The thermogravimetric experiment enables to determine both the TG curve $(m(t))$ and the DTG curve $(\dot{m}(t))$. It is thus possible to plot at any time the value of the total heat of desorption as a function of the mass:

$\Delta H_{t}(t)=f(m(t))$.

It must be reminded that the heat of sorption is an average heat calculated at the average temperature of the sample and for an average moisture concentration. The more accurate assumptions A1 and A2 are, the more Eq. (24) may be considered valid.

\subsection{Determination of the sorption isotherm}

To determine the sorption isotherm, three measurements are needed: temperature, mass and water activity of the sample. Of these three parameters, only the mass can be easily determined with a thermobalance. The temperature of the furnace is an approximate value of the actual temperature of the sample. The water activity is not known. A protocol to determine all three parameters from a simultaneous TG-DSC measurement is presented herein. The method used is based on the same experiment $(S)$ as described above.

A new assumption is used in this section:

A3: Evaporation of water occurs according to the stagnant film theory (Bird et al., 1960). This assumption will also be discussed in Section 5.

The stagnant film theory (Bird et al., 1960) is used to model the evaporation of water in experiment $(\mathrm{S})$ :

$\dot{m}=\Gamma \ln \left(\frac{p-p_{v}}{p-a_{w} p_{\text {sat }}\left(T_{S}\right)}\right)$.

In Eq. (25) the vapour partial pressure $p_{v}$ in the furnace is fixed, and the partial pressure at the surface of the sample is the product of the surface water activity $a_{w}$ and the water vapour pressure $p_{\text {sat }}\left(T_{S}\right)$ at the temperature of the sample. The coefficient:

$\Gamma=\frac{M_{v} D_{v}\left(T_{S}\right) A p}{R T_{S}(L-e)}$

is a function of the temperature in the crucible $T_{S}$ and the length of diffusion $L-e$ between the sample free surface $A$ and the edge of the crucible (Fig. 2). The vapour-air diffusion coefficient $D_{v}$ is calculated at the sample temperature $T_{S}$ by the following equation (Berman, 1961):

$D_{v}=2.26 \times 10^{5} \frac{1}{p}\left(\frac{T_{S}}{273}\right)^{1.81}$

with $T_{S}$ in Kelvin, $p$ in bar, $D_{v}$ in $m^{2} s^{-1}$.

The calculation of coefficient $\Gamma$ requires a correct precision on the value of the sample temperature $T_{S}$. This

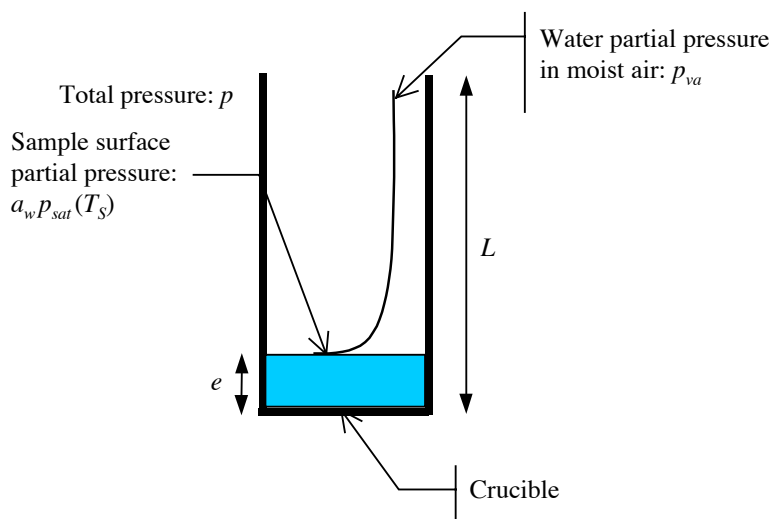

Fig. 2. Partial pressure profile according to the stagnant film theory in the sample crucible $(\mathrm{S})$.

temperature may be computed from the calorimetric signal $\dot{q}_{c}$ and the furnace temperature $T_{F}$ using Eq. (18):

$T_{S}=T_{F}+\frac{\dot{q}_{c}}{\mathrm{UA}_{S}}$.

The product thickness $e$ is a function of time. It can be derived from the mass of sample:

$e=\frac{m(t)}{\rho A}$,

where $\rho$ is an average constant density of sample. Using Eq. (25), a direct calculation of $a_{w}$ leads to the following expression:

$a_{w}=\frac{p}{p_{\mathrm{sat}}(T s)}(\exp (\dot{m} / \Gamma)-1)+\frac{p_{v^{\infty}}}{p_{\mathrm{sat}}\left(T_{S}\right)}$.

The sorption isotherm is thus the plot of $a_{W}$ (defined by Eq. (30)) as a function of the sample moisture content (Eq. (2)), for the corrected temperature $T_{S}$.

The vapour partial pressure in the furnace can be calculated assuming a perfect mixing of the transfer gas and the water vapour:

$p_{v}=\frac{\left(\dot{m} / \dot{m}_{a}\right) p}{M_{v} / M_{a}+\dot{m} / \dot{m}_{a}}$,

where $\dot{m}_{a}$ is the mass flowrate of the transfer gas (dry air).

\section{Experimental results}

In order to avoid concentration gradients during the short heating period, pure water is disposed on the pasty sample. The surface must be as plane as possible and a low thickness is required. Typically $3-7 \mathrm{mg}$ of dry mass samples are used. The calorimetric signal $\dot{q}$ and the TG signals $m(t)$ are recorded simultaneously (Experiment $\mathrm{S}$ ). The DTG signal $\dot{m}(t)$ is calculated by the software associated with the apparatus. The corrected calorimetric signal $\dot{q}_{C}$ is calculated using $\dot{q}_{B}$ obtained from the blank experiment (Experiment B). 


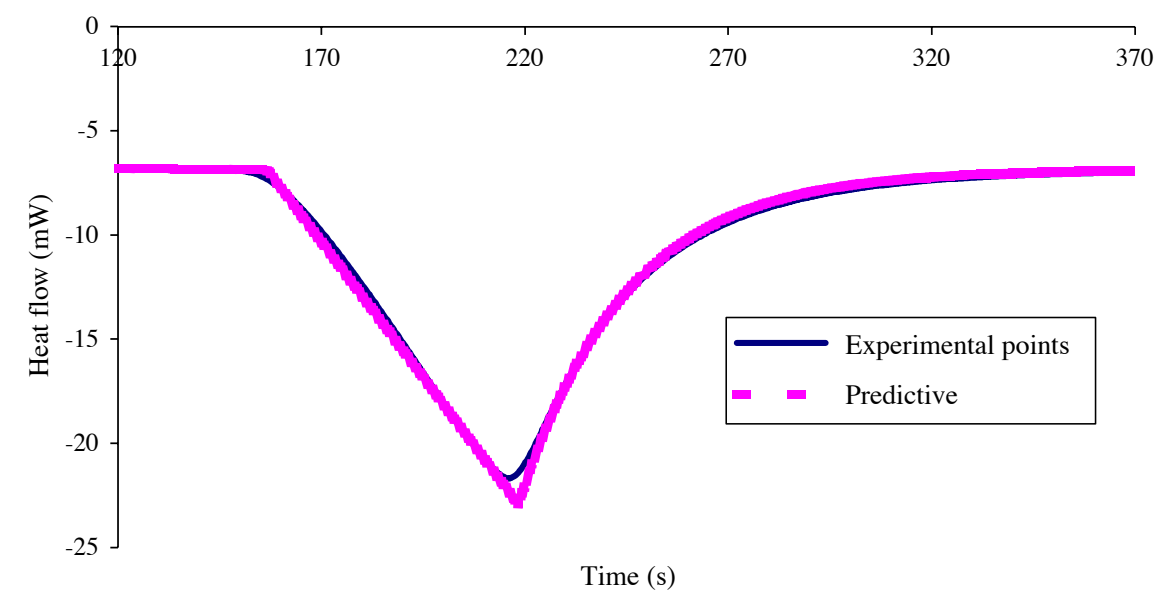

Fig. 3. Comparison of theoretical and experimental heat flow for a fusible medium. The melting region corresponds to the first part of the curve.

\subsection{Experimental determination of the heat transfer coefficient in the crucible}

An estimation of the heat transfer coefficient may be obtained from a specific experimental procedure (Experiment $\mathrm{F}$ ). A fusible medium is used in the same range of temperature as in experiment S and B (Section 3.1) and the microcalorimeter is used in scanning mode with a constant heating rate $\bar{v}$. During the phase change, the temperature of the sample remains equal to the phase change temperature $T_{C}$ while the furnace temperature varies linearly with time (Gray, 1968; Speyer, 1994).

The overall heat transfer coefficient may be written (Gray, 1968):

$(\mathrm{UA})_{S}=-\left.\frac{1}{\overline{\mathrm{v}}} \frac{\mathrm{d} \dot{q}}{\mathrm{~d} t}\right|_{\text {melting }}$,

where $\left.\frac{\mathrm{d} \dot{q}}{\mathrm{~d} t}\right|_{\text {melting }}$ is the slope of the calorimetric signal at the beginning of the melting process. To determine $\mathrm{UA}_{S}$ in the appropriate range of temperature, a sample of pure indium of fusion temperature $T_{C}=156.6^{\circ} \mathrm{C}$ is used and the heat transfer coefficient is fitted using Eq. (32).

The comparison of the computed value using and the experimental corrected heat flow is shown in Fig. 3. The agreement between the two curves is very good, in spite of the simplicity of the model (constant heat transfer coefficient, temperature uniformness). When the sample reaches the melting temperature, the sample remains at constant temperature until the phase change is completed.

\subsection{Determination of sorption isotherms for MCC and Kaolin}

Validation experiments were conducted on two products. The first product is MCC because it has been chosen as a reference material in food and pharmaceutical studies. The

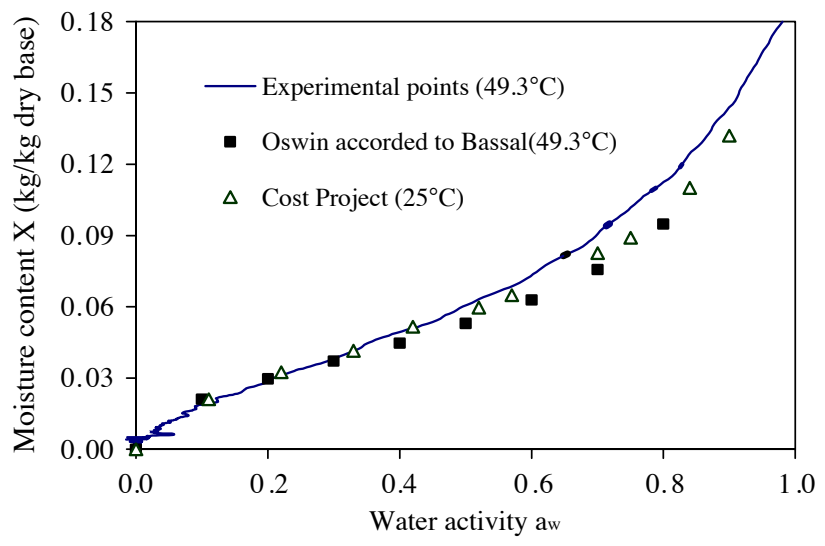

Fig. 4. Comparison of sorption isotherm for $\mathrm{MCC}$ for $T_{F}=50^{\circ} \mathrm{C}$.

second product is kaolin because extensive data on this product were found in the literature (Kroes, 1999).

$M C C$ : Results for $\mathrm{MCC}$ are obtained at two furnace temperatures $T_{F}=50^{\circ} \mathrm{C}$ and $100^{\circ} \mathrm{C}$. For $T_{F}=50^{\circ} \mathrm{C}$, the temperature correction (Eq. (29)) is small and the average temperature during the experiment is $T_{S}=49.3{ }^{\circ} \mathrm{C}$. Although not originally valid in this range of temperature, these data were compared (Fig. 4) to Oswin model using the original set of parameters obtained by Bassal (1993) reproduced in Annex 1. The results from the COST project (Wolf et al., 1984) are also shown at a lower temperature $T_{S}=25^{\circ} \mathrm{C}$. These data are also consistent with the data obtained with the present method, which seems to prove that the temperature shift of the isotherms is not very significant. It must be emphasized that the present method could not be used at such a low temperature of $T_{S}=25^{\circ} \mathrm{C}$ because of the lack of sensitivity of the thermobalance for small mass flowrates. However, there is a good agreement between these two sets of data and the present experimental method, especially for small values of the activity $\left(0 \leqslant a_{w} \leqslant 0.4\right)$. 


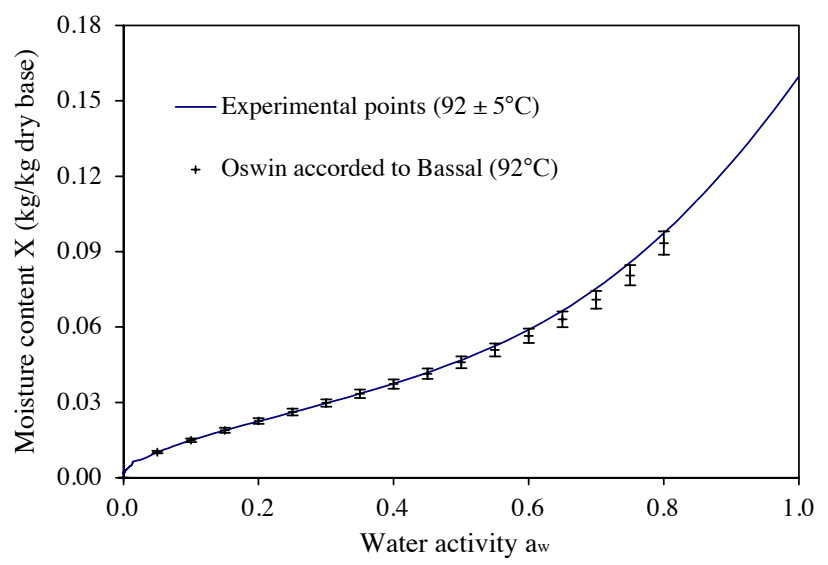

Fig. 5. Comparison of sorption isotherm for MCC.

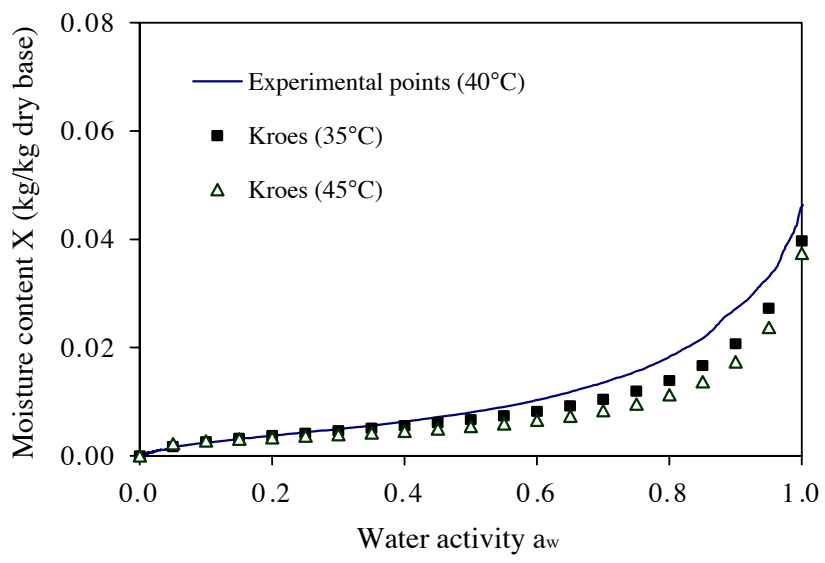

Fig. 6. Comparison of sorption isotherm for Kaolin.

At a higher temperature, the drying rate is important and the temperature difference between the furnace and the sample is more significant. But the temperature shift of the isotherms is still small and thus temperature changes do not affect significantly the quality of the results as long as these changes can be quantified. Results for an average sample temperature $T_{F}=92^{\circ} \mathrm{C}$ are presented in Fig. 5. The temperature of the sample has been calculated according to Eq. (28) and was estimated at $92 \pm 5^{\circ} \mathrm{C}$ during the whole experiment. These data are comparable to the original set of data obtained by Bassal (1993) with Oswin's model. (Annex 1). The error was estimated by Bassal (1993) and reproduced on the graph. The agreement between the two sets of experiments is very good in this range of temperature especially for $a_{w} \leqslant 0.8$. For $a_{w} \geqslant 0.8$, the equilibrium method is very difficult to achieve and no results are available in the literature. The present method allows to determine actual values of $a_{w}=f(X, T)$ even at $a_{w} \cong 1$, but there is no indication on the error made.

Kaolin: Results for kaolin are shown in Fig. 6. The furnace temperature is set at $T_{F}=40^{\circ} \mathrm{C}$. As for MCC, measurements at lower temperatures are difficult to obtain because of the

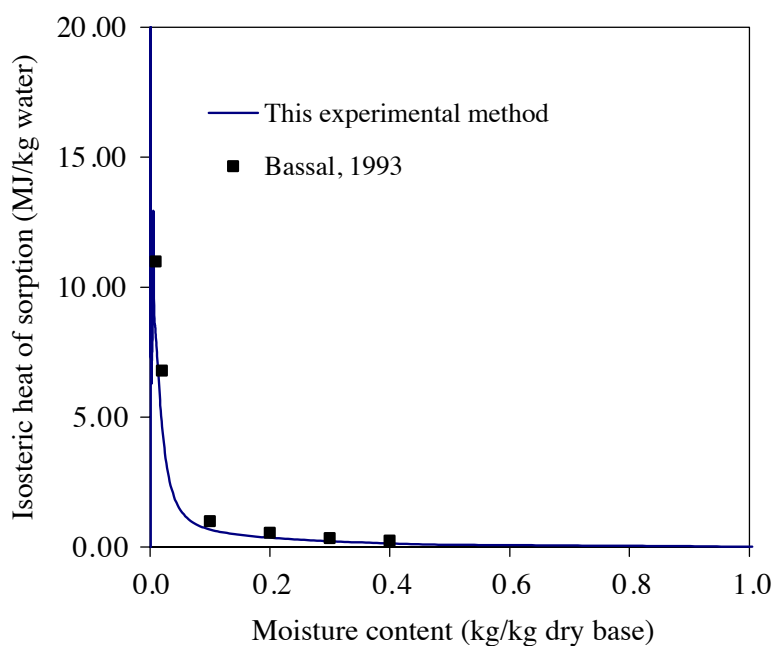

Fig. 7. Comparison of isosteric heat of desorption for MCC for low moisture content

lack of sensitivity of the thermobalance. These data were compared with results obtained by Kroes (1999) at similar temperatures (Annex 1). Although the general shapes of the curves are very similar, a good match is only observed for small values of $a_{w}$ typically $a_{w} \leqslant 0.25$. The origin of this discrepancy (internal transfer limitations) will be discussed in Section 5.

\subsection{Determination of the isosteric heat of sorption for $M C C$}

In the case of the isosteric heat of sorption, reliable data for MCC were found in Bassal (1993). These data were obtained using a formal differentiation of Eq. (6). Results are shown in Fig. 7 at $95^{\circ} \mathrm{C}$.

It has been emphasized in Section 1 that the indirect methods led to important errors in the determination of $\Delta H_{\mathrm{st}}$. However, in spite of a $25 \%$ error for low water contents, the agreement between the two methods is very good. In particular, it can be seen that for $X \geqslant 0.4$, adsorption effects become negligible and the isosteric heat of sorption $\Delta H_{\mathrm{st}}$ is equal to zero. The method can thus also be used to quantify the transition moisture content between free and bound water in a biological materials undertaking a desorption process, which cannot be obtained with accuracy from typical S-shaped sorption isotherms for food and biological materials.

\section{Discussions}

The good estimation of heat and mass transfer parameters requires the validity of the three mains assumptions $\mathrm{A} 1-\mathrm{A} 3$ given in Section 3. For the external transfer, the relevant parameters are the overall heat transfer coefficient (UA) $S$ and the mass transfer coefficient between the furnace and the 


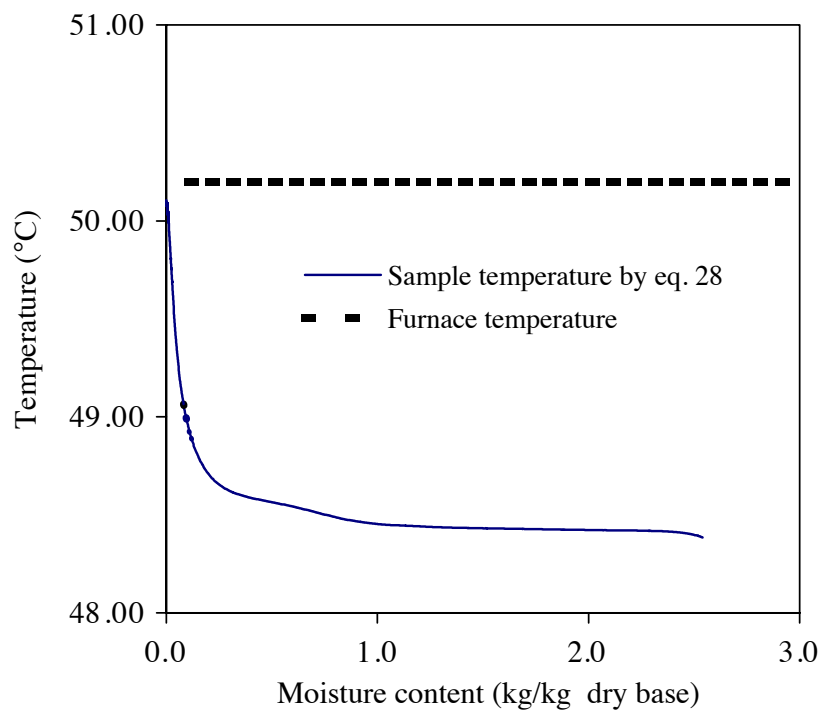

Fig. 8. Sample temperature as a function of the water content during sorption measurement.

crucible. These coefficients are not related by laws of similarity because the heat and mass transfer areas are different. Internal heat transfer can be quantified by the thermal conductivity $k$ and the effective water diffusivity $D_{S}$ of the sample.

\subsection{Heat transfer assumptions}

\subsubsection{Temperature uniformness in the sample}

An important condition for the application of Eqs. (7)(24) is the uniformness of the temperature in the sample which is achieved for $\mathrm{Bi}_{T}=(\mathrm{UA})_{S} e / A_{T} k \leqslant 0.1$, where $\mathrm{Bi}_{T}$ is the thermal Biot number.

With the typical values of (UA) $)_{S}, e$ and $A_{T}$, this condition is fulfilled for $k \geqslant 3 \cdot 10^{-3} \mathrm{~W} \mathrm{~m} \mathrm{~m}^{-1} \mathrm{~K}^{-1}$, which is always valid for biological and food materials.

\subsubsection{Sample temperature change}

Although the calorimeter furnace is kept isothermal, the endothermic desorption effect creates a temperature difference between the furnace and the sample. This temperature difference is larger at the beginning of the desorption process and becomes smaller and smaller as water activity decreases. Using Eq. (28), the sample temperature is computed for experiment S. In Fig. 8 kaolin is desorbed at $T_{F}=50^{\circ} \mathrm{C}$ and the actual temperature of the sample is plotted versus the moisture content $X$. An average temperature of $T_{S}=49.3 \pm 0.9^{\circ} \mathrm{C}$ is observed. For a higher temperature of furnace $\left(T_{F}=92^{\circ} \mathrm{C}\right)$ the temperature deviation is $\pm 5^{\circ} \mathrm{C}$. Compared to equilibrium sorption measurement techniques for which the error on the temperature is small $\left( \pm 0.5^{\circ} \mathrm{C}\right)$, the present method does not allow a good stabilization of the temperature, but according to Weisser (1986), the sensitivity of sorption isotherms to temperature changes is small.

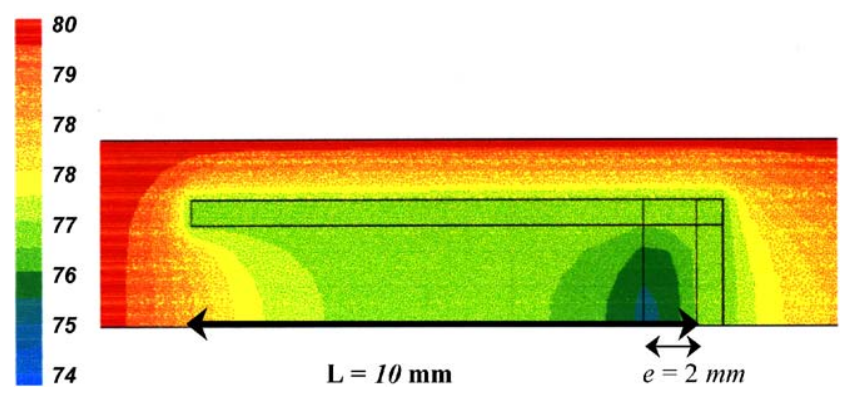

Fig. 9. Temperature field in the crucible using FLUENT calculation for $T_{F}=80^{\circ} \mathrm{C}$, and a gas flowrate of $0.51 / \mathrm{h}$.

More important is the fact that the sample temperature is different from the furnace temperature and can be calculated from Eq. (28) at any time.

\subsubsection{Temperature uniformness of the gas trapped in the crucible}

To be able to apply the stagnant film theory (Section 5.3), the assumption of isothermal conditions in the gas trapped in the crucible must be valid. A CFD model (FLUENT) has been used to determine the temperature field in the crucible and the furnace. To account for the endothermic reaction in the sample, a source term was applied in the sample. The furnace temperature was set to $80^{\circ} \mathrm{C}$ and a gas laminar flow was applied $\left(0.5 \mathrm{~L} \mathrm{~h}^{-1}\right)$. It is shown in Fig. 9 that the gas temperature in the furnace upstream of the crucible reaches rapidly the furnace temperature, due to the low gas velocities. It is also shown that the gas temperature inside the crucible is close to the sample temperature, thus the assumption of isothermal gas in Eq. (25) is valid in the conditions of the experiment.

\subsection{Mass transfer assumptions}

\subsubsection{External mass transfer}

In order to improve the stagnant film approximation, a new experimental protocol, very similar to experiment $(\mathrm{P})$ previously described, was performed with pure water.

This experiment allowed to compare the evaporation rate $\dot{m}_{\text {exp }}(t)$ from TG experiments and the calculated evaporation rate $\dot{m}(t)$ obtained using Eqs. (26)-(28) with $a_{w}=1$. Corrections were used for temperature (Eq. (28)), product thickness (Eq. (29)), partial vapour pressure (Eq. (31)). As seen in Fig. 10, there is a very good agreement between the computed mass flow rate and the experimental mass flowrate which validates the stagnant film model and the correction made for temperature and thickness change.

\subsubsection{Internal mass transfer}

An important assumption is the assumption of a homogeneous moisture concentration in the sample. Internal diffusion is responsible for concentration gradients. Thus a difference should be observed between the average moisture 


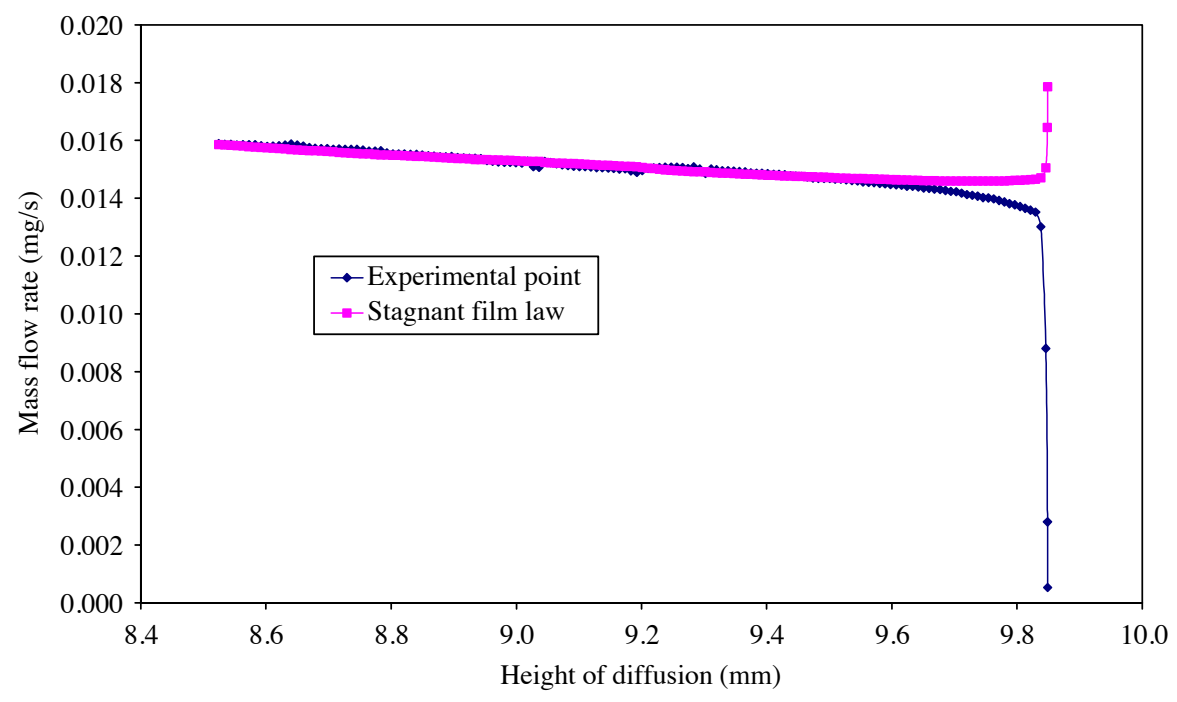

Fig. 10. Comparison between experimental mass rate for pure water and calculations using the stagnant film law.

content measured by the thermobalance and the local superficial moisture concentration which is in equilibrium with the flowing moist air. It is assumed that the sorption isotherms can be locally approximated by a straight line: $\partial a_{w} / \partial X=C$. For poorly adsorptive materials $C$ is large and for highly adsorptive materials $C$ is small.

With these assumptions, convective and adsorptive effects can be lumped into an overall mass transfer coefficient $K$ defined by

$K=C \frac{M_{v} P_{V \text { sat }}\left(T_{S}\right) e A}{\dot{m}_{a} R T_{S}} \cdot \frac{D_{v}\left(T_{S}\right)}{L-e}$.

A mass Biot number can be introduced based on $K$ and the material thickness $e$ :

$\mathrm{Bi}_{m}=\frac{K e}{D_{s}}$.

The mass Biot number compares the internal mass transfer and the external mass transfer. It is generally assumed that internal concentration gradients may be neglected when $\mathrm{Bi}_{m}<0.1$. Therefore the Biot number was calculated for the experiments with MCC and Kaolin. The value for $C$ for each experimental point was derived from the slope of the experimental sorption isotherm. $D_{v}\left(T_{S}\right)$ and $e$ were calculated using the set of Eqs. (28)-(31).

For Kaolin, the internal diffusion coefficient is reported in the appendix (Kroes, 1999). The following experimental values where used: $A=1.25 \times 10^{-5} \mathrm{~m}^{2}, L=10^{-2} \mathrm{~m}$, $m_{0}=11.11 \times 10^{-6} \mathrm{~kg}$. For the experiments reported in Fig. 6, the range of the mass Biot number is 2-100 which is well above the critical value of 0.1 although the comparisons are satisfactory especially for small activities, thus low moisture contents. The most satisfying explanation is that the characteristic thickness of the sample is one or two decades smaller than the calculated thickness $e$ due to cracks, bubbles and surface effects that are observed when the medium shrinks and dries. At larger activities, the internal apparent mass diffusion coefficient is larger but the value of $e$ is more relevant to calculate the Biot number and describe the mass transfer process.

For MCC $\left(m_{0}=6.6933 \times 10^{-6} \mathrm{~kg}\right)$, only one diffusion coefficient was reported in the literature $\left(D_{s}=1.26 \times\right.$ $10^{-9} \mathrm{~m}^{2} \mathrm{~s}^{-1}$ from Sun et al., 1993), but no mention was made of the conditions of the experiment. However the results are better than for Kaolin (Figs. 4 and 5), but it is difficult to give a straightforward explanation to the excellent results obtained with MCC.

Due to internal diffusion, the average water activity is higher than the local water activity at the surface of the sample, thus the average moisture content is higher than the local moisture content at the surface of the sample. The present method produces a plot of the average moisture content versus the local surface activity. Compared to static methods, the sorption isotherm is thus shifted upwards for most experiments (Figs. 4-6).

However, the method described in the present paper seems well adapted for pasty materials that contain important amount of waster (gels, colloïds, paste, sludge...) with a mass transfer limitation when the internal diffusion coefficients is smaller than $10^{-10} \mathrm{~m}^{-2} \mathrm{~s}^{-1}$. The method has been applied with success (Ferrasse, 2000), to the determination of sorption isotherms of sludge in the conditions of high temperature drying $\left(100^{\circ} \mathrm{C}\right)$.

\section{Conclusion}

Calorimetric and gravimetric signals from a Setaram DSC111 set-up in isothermal mode were used to build sorption isotherms and heat of sorption calculations for water in standard materials (microcrystalline cellulose and kaolin). Unlike most experimental techniques which are based on thermodynamic equilibrium and yield a limited number of 
experimental points, the developed method uses a dynamic approach and yields continuous functions. Although temperature stability in the sample is difficult to achieve due to the evaporation effect, temperature shifts have little effect on the sorption isotherms. The sample is small enough to allow temperature homogeneity even with low thermal conductivity materials. With respect to mass transfer, pasty or colloïdal materials have smaller diffusion coefficients at lower moisture contents thus lower activities but the validity of the method is better at low activities $\left(0 \leqslant a_{w} \leqslant 0.4\right)$. This surprising result suggests that the characteristic length at low moisture content is much smaller than the theoretical thickness of the sample due to cracks, bubbles and surface effects in the tested media. The accuracy is also enhanced at higher temperatures $\left(T \geqslant 40^{\circ} \mathrm{C}\right)$, first because of a better sensitivity of the microbalance and flowmeters, but also because of higher internal diffusion rates. Unlike most values found in environmental or food engineering, the isosteric heat of desorption is not derived from the shift of sorption isotherms with temperature but from direct measurements. The data for the heat of sorption suffer from a lack of comparison but direct measurement instead of calculations would give more precise and effective information for the design and calculation of dryers at low moisture ranges. The residence time of the sample in the DSC cell is small (typically a few hours for a complete experiment), which makes it suitable for the prediction of thermodynamic properties of heat and moisture sensitive products like food or sludge, whereas more conventional methods would lead to misleading interpretations due to the conjunction of biological activity, temperature and residence time effects.

\section{Notation}

\begin{tabular}{|c|c|}
\hline$a_{w}$ & water activity \\
\hline$A$ & mass exchange area, $\mathrm{m}^{2}$ \\
\hline$A_{T}$ & heat exchange area, $\mathrm{m}^{2}$ \\
\hline $\mathrm{Bi}_{T}$ & thermal Biot number \\
\hline $\mathrm{Bi}_{m}$ & mass Biot number \\
\hline$c$ & heat capacity, $\mathrm{J} \mathrm{kg}^{-1} \mathrm{~K}^{-1}$ \\
\hline$D_{v}$ & water diffusion coefficient in air, $\mathrm{m}^{2} \mathrm{~s}^{-1}$ \\
\hline$D_{S}$ & water diffusion coefficient in sample, $\mathrm{m}^{2} \mathrm{~s}^{-1}$ \\
\hline$e$ & sample thickness, $\mathrm{m}$ \\
\hline$k$ & thermal conductivity of sample, $\mathrm{W} \mathrm{m}^{-1} \mathrm{~K}^{-1}$ \\
\hline$L$ & height of crucible, $\mathrm{m}$ \\
\hline$m$ & mass of sample, $\mathrm{kg}$ \\
\hline$m_{0}$ & dry mass of sample, $\mathrm{kg}$ \\
\hline$\dot{m}_{a}$ & air flowrate, $\mathrm{kg} \mathrm{s}^{-1}$ \\
\hline$M$ & molar mass, $\mathrm{kg} \mathrm{mol}^{-1}$ \\
\hline$p$ & total pressure, $\mathrm{Pa}$ \\
\hline$p_{v}$ & water partial pressure, $\mathrm{Pa}$ \\
\hline$p_{\text {sat }}$ & water boiling pressure, $\mathrm{Pa}$ \\
\hline$\dot{q}$ & heat flow, W \\
\hline$R$ & ideal gas constant, $\mathrm{J} \mathrm{mol}^{-1} \mathrm{~K}^{-1}$ \\
\hline
\end{tabular}

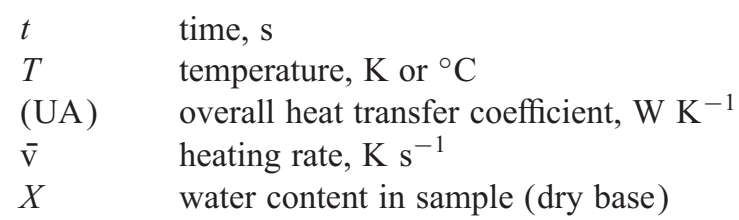

Greek letters

$\begin{array}{ll}\Delta H & \text { heat, } \mathrm{J} \mathrm{kg}^{-1} \\ \mu & \text { heat capacity, } \mathrm{J} \mathrm{K}^{-1} \\ \rho & \text { density, } \mathrm{kg} \mathrm{m}^{-3}\end{array}$

\section{Subscripts}

$\begin{array}{ll}a & \text { air } \\ B & \text { blank experiment } \\ C & \text { corrected experiment } \\ F & \text { furnace } \\ R & \text { reference } \\ S & \text { sample or solid } \\ t & \text { total } \\ \text { st } & \text { isosteric } \\ v & \text { vapour phase }\end{array}$

Appendix A. Referenced correlations used for comparison of sorption isotherm and internal coefficient diffusion

\section{A.1. MCC (Microcellulose crystalline)}

Sorption isotherms: Results are reported from Bassal (1993) and fitted by Oswin model. The temperature range is $80-150^{\circ} \mathrm{C}$ :

$K_{1}=6.0585$

$K_{2}=-1.5927 \times 10^{-2}$

$K_{3}=0.3198$

$K_{4}=2.0875 \times 10^{-3}$,

$X=\left(K_{1}+K_{2} T\right)\left(K_{3}+K_{4} T\right) \frac{a_{w}}{1-a_{w}}$, with $T$ in ${ }^{\circ} \mathrm{C}$.

The relative error for this Oswin law with experimental data was $5.5 \%$.

\section{A.2. Kaolin}

(a) Sorption isotherm: Results are reported from Bas Kroes (1999) and fitted by the GAB model. The temperature 
range is $35-55^{\circ} \mathrm{C}$ :

$$
\frac{X}{X_{\text {mono }}}=\frac{C_{\text {gug }} k a_{w}}{\left(1-k a_{w}\right)\left(1-k a_{w}+C_{\text {gug }} k a_{w}\right)},
$$

no relative errors are reported :

\begin{tabular}{llc}
\hline Gab-parameters & Temperature & \\
\hline$k$ & $35^{\circ} \mathrm{C}$ & 0.9 \\
$k$ & $45^{\circ} \mathrm{C}$ & 0.92 \\
$C_{\text {gug }}$ & $35^{\circ} \mathrm{C}$ & 15 \\
$C_{\text {gug }}$ & $45^{\circ} \mathrm{C}$ & 53.4 \\
$X_{\text {mono }}$ & $35^{\circ} \mathrm{C}$ & 0.004 \\
$X_{\text {mono }}$ & $45^{\circ} \mathrm{C}$ & 0.003 \\
\hline
\end{tabular}

(b) Internal diffusion coefficient for bound water, i.e. for moisture such as $a_{w}<1$ (Bas Kroes, 1999):

$a=-1.38$,

$b=-9.013 \times 10^{-1}$,

$c=-4.96$,

$d=-1.37 \times 10^{-2}$

$e=1.567$

$\log _{10} D=a+b \ln X+\frac{c}{\ln X}+d(\ln u)^{2}+\frac{e}{(\ln u)^{2}}$.

The temperature effect is described with the Arrhenius equation. A constant activation energy of $3 \times 10^{4} \mathrm{~J} \mathrm{~mol}^{-1}$ is used.

\section{References}

Balaban-Murat, O., Zuritz-Carlos, A., Singh, R.P., Hayakawa, K., 1987. Estimation of heat of moisture sorption and improved criteria for evaluating moisture sorption isotherm equations for food. Journal of Food Process Engineering 10 (1), 53-70.

Bassal, A., 1993. Etude de l'activite de l'eau dans les aliments au-dessus de $100^{\circ}$ C. Ph.D. Dissertation, Ecole Nationale Superieure des Industries Agricoles et Alimentaires (in French).

Bassal, A., Vasseur, J., Loncin, M., 1993. Sorption isotherms of food materials above $100^{\circ} \mathrm{C}$. Lebensmittel-Wissenschaft-und-Technologie 26 (6), 505-511.

Baucour, P., Daudin, J.D., 1999. Development of a new method for fast measurement of water sorption isotherms in the high humidity range. Validation on gelatine gel. Journal of Food Engineering 44 (2), 97-107.

Beristain, C.I., Azuara, E., Garcia, H.S., Vernon-Carter, E.J., 1999. Determination of moisture enthalpy of mesquite gum with differential scanning calorimetry and thermogravimetric analysis. Drying technology 17 (4), 937-945.

Berlier, K., Frère, M., 1996. Adsorption of CO2 on activated carbon: simultaneous determination of integral heat and isotherm of adsorption. Journal of Chemical and Engineering Data 41 (5), 1144-1148.

Berman, L.D., 1961. Evaporative Cooling of Circulating Water. Pergamon Press, New York

Bird, R.B., Stewart, W.E., Lightfoot, E.N., 1960. Transport Phenomena. Wiley, New York
Calvet, E., Prat, H., 1956. Microcalorimétrie. Applications Physico-chimiques et Biologiques. Masson et Cie, Paris.

Calvet, E., Prat, H., 1963. Recent Progress in Microcalorimetry. Pergamon Press, Oxford.

Chirife, J., Iglesias, H.A., 1992. Estimation of the precision of isosteric heats of sorption determined from the temperature dependence of food isotherms. Lebensmittel-Wissenschaft-und-Technologie 25 (1), 83-84.

Collins, E.M., 1933. The partial pressures of water in equilibrium with aqueous solutions of sulfuric acid. Journal of Physical Chemistry 37, 1191-1203.

Ferrasse, J.-H., 2000. Développement d'outils expérimentaux pour le dimensionnement de procédés de séchage conductif avec agitation: application à des boues de stations d'épurations urbaines. Ph.D. Dissertation, Université Paul Sabatier, Toulouse, France (in French).

Ferrasse, J.H., Arlabosse, P., Lecomte, D., Schwartzentruber, J., 2000a. Apport $\mathrm{du}$ couplage d'une thermobalance gravimétrique et d'un analyseur calorimétrique différentiel pour la mesure de l'activité de l'eau dans un mélange liquide-solide. Entropie 224-225, 80-85.

Ferrasse, J.H., Arlabosse, P., Lecomte, D., 2000b. Direct total heat of sorption measurement from coupled TGA-DSC analysis. In: Do, D.D. (Ed.), Adsorption Science and Technology. World Scientific, Singapore, pp. 366-370.

Franks, F., 1991. Hydration phenomena: an update and implications for the food processing industry. In: Levine, H., Slade, L. (Eds.), Water Relationships in Food. Plenum, New York, pp. 1-19.

Gray, A.P., 1968. A simple generalized theory for the analysis of dynamic thermal measurement. In: Porters, R.F., Johnson, J.M. (Eds.), Analytical Calorimetry. Plenum, New York, pp. 209-218.

Ibeka, J.C., Blaisdell, J.L., 1982. Moisture isotherms of a processed meat product-Bologna. J. Food Technol. 17, 37.

Iglesias, H.A., Chirife, J., 1982. Handbook of Food Osotherms: Water Sorption Parameters for Food and Food Components. Academic Press, New York.

Iglesias, H.A., Chirife, J., Ferro Fontan, C., 1989. On the temperature dependence of isosteric heats of water sorption in dehydrated foods. Journal of Food Science 54, 1620-1624.

Jowitt, R., Wagstaffe, P.J., 1989. The certification of water content of microcrystalline cellulose (MCC) at 10 water activities. Technical Report, Commission of the European Communities.

Kroes, B., 1999. The influence of material properties on drying kinetics. Ph.D. Dissertation, Technical University of Eindhoven, The Netherlands (in English).

Landrock, A.H., Proctor, B.E., 1951. Measuring humidity equilibria. Modern Packaging 24, 123-130.

Leung, H.K., 1983. Water activity and other colligative properties of foods. ASAE Annual Meeting, Chicago, II, December 13-16, Paper no. $83-6508$

Loncin, M., 1988. Activity of water and its importance in preconcentration and drying of foods. In: Bruin, S. (Ed.), Proceedings of the International Symposium on Preconcentration and Drying of Foods, Eindhoven, The Netherlands, November 5-6, 1987. Elsevier, Amsterdam.

Méot, J.-M., Bimbenet, J.-J., Abécassis, J., 1996. Rapid determination of sorption isotherms and water apparent diffusivity. Drying Technology 14 (9), 2003-2023.

Mulet, A., Garcia-Reverter, J., Sanjuan, R., Bon, J., 1999. Sorption isosteric heat determination by thermal analysis and sorption isotherms. Journal of Food Science 64 (1), 64-68.

Othmer, D.F., 1940. Correlating vapour pressure and latent heat data. A new plot. Industrial and Engineering Chemistry 32, 841-856.

Prior, B.A., 1979. Measurement of water activity in foods: a review. Journal of Food protection 42, 668-674.

Rahman, S., 1995. Food properties handbook. CRC Press, Boca Raton.

Rao, M.A., Rizvi, S.S.H., 1986. Engineering properties of food. Marcel Dekker, New York

Rouquerol, F., Rouquerol, J., Sing, K., 1999. Adsorption by Powders and Porous Solids. Academic Press, New York.

Speyer, R.F., 1994. Thermal Analysis of Materials. Marcel Dekker, New York, p. 86 (Chapter 3). 
Sun, X., Litchfield, J.B., Schmidt, S.J, 1993. Temperature mapping in a model food gel using magnetic resonance imaging. J-Food-Sci-Off-Publ-Inst-Food-Technol. Chicago, II: The Institute 58 (1), 168-172, 181.

Tian, A., 1924. Microcalorimètre à compensation par effets Peltier et Joule. Bulletin de la Societe de Chimique 33, 427.

Vaxelaire, J., Mousques, P., Bongiovanni, J.-M., Puiggali, J.-R., 2000. Desorption isotherms of domestic activated sludge. Environmental Technology 21, 327-335.

Viollaz, P.F., Rovedo, C.O., 1999. Equilibrium sorption isotherms and thermodynamic properties of starch and gluten. J. Food Engineering 40, 287-292.
Weisser, H., 1986. Influence of temperature on sorption isotherms. In: Le Maguer, M., Jelen, P. (Eds.), Food Engineering and Process Applications. Elsevier, New York.

Wolf, W., Spiess, W.E.L., Jung, G., Wiesser, H., Bizot, H., Duckworth, R.B., 1984. The water-vapour sorption isotherms of mycrocrystalline cellulose (MCC) and of purified potato starch. Results of a collaborative study. Journal of Food Engineering 3, 51-73.

Wolf, W., Spiess, W.E.L., Jung, G., 1985. Sorption Isotherms and Water Activity of Food Materials: A Bibliography. Science and Technology, Hornchurch, England. 